\title{
ESG, Risk, and (tail) dependence
}

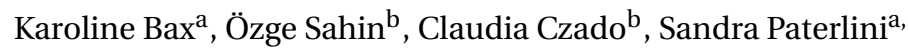

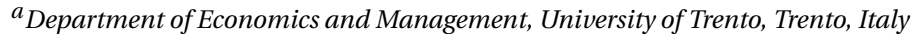

${ }^{b}$ Department of Mathematics, Technical University of Munich, Munich, Germany

\begin{abstract}
While environmental, social, and governance (ESG) trading activity has been a distinctive feature of financial markets, the debate if ESG scores can also convey information regarding a company's riskiness remains open. Regulatory authorities, such as the European Banking Authority (EBA), have acknowledged that ESG factors can contribute to risk. Therefore, it is important to model such risks and quantify what part of a company's riskiness can be attributed to the ESG scores. This paper aims to question whether ESG scores can be used to provide information on (tail) riskiness. By analyzing the (tail) dependence structure of companies with a range of ESG scores, that is within an ESG rating class, using high-dimensional vine copula modelling, we are able to show that risk can also depend on and be directly associated with a specific ESG rating class. Empirical findings on real-world data show positive not negligible ESG risks determined by ESG scores, especially during the 2008 crisis.
\end{abstract}

Keywords: ESG scores, Risk, Dependence, Tail dependence, Vine Copula models JEL classification: G32, C51, C58

\section{Introduction}

After the 2007-2009 financial crisis, many models which used to capture the dependence between a large number of financial assets were revealed as being inadequate during crisis. Moreover, research has shown that the dependence structure of global financial markets has grown in importance in areas of optimal asset allocation, multivariate asset pricing, and portfolio tail risk measures $(\mathrm{Xu} \& \mathrm{Li}, 2009)$. Consequently, the enormous losses and the increased volatility in the global financial market elicited calls for an even more diligent risk management.

Over the past decade, the interest in socially responsible investments has grown exponentially (Auer \& Schuhmacher. 2016). The availability of non-financial data, including corporate social responsibility (CSR) or environmental, social, and governance (ESG) data, has skyrocketed and gained interest from investors for various reasons. According to Li \& Polychronopoulos 2020), in 2019, 70 different firms were identified as providers of some sort of ESG rating. While some studies are pointing out ambiguity and divergence between these different ratings (see 
Berg et al. 2019, 2021); Billio et al. (2021); Gibson et al. 2020); Serafeim \& Yoon (in press), the overall idea of ESG scores is to indicate a level of ESG performances. These scores are based on several criteria and measurements and are given by a rating institution (Bhattacharya \& Sharma 2019). The rating institutions use quantitative and qualitative methods to assign an ESG score to a company (Berg \& Lange, 2020). In brief, companies are awarded large scores for ESG responsible behavior but are awarded low scores for ESG irresponsible behavior. Typically a company is associated with a rating class (i.e., $A, B, C$, or $D$ ) based on its ESG score value using thresholds or quartiles. Then, companies with the same ESG score or ESG scores within the same threshold or quartile are allocated in the same ESG rating class. Acting as complementary non-financial information, ESG scores can have the potential to increase the accuracy in performance forecasts and risk assessments Achim \& Borlea. 2015.

In 2018, the European Commission published its Action Plan on Financing Sustainable Growth which provided the European Union (EU) with a roadmap on sustainable finance and for future work across financial systems ropean Banking Authority 2018. Furthermore, the increase in demand in socially responsible investments stems from investors and asset managers pressured by stakeholders to push companies to behave responsibly and improve their ESG strategy (Henriksson et al. 2019). The biennial 2018 Global Sustainable Investment Review states that over \$30 trillion had been invested with explicit ESG goals Global Sustainable Investment Alliance (GSIA) 2018. According to a 2018 global survey, more than $50 \%$ of the international asset owners are currently considering or already implementing ESG scores in their investment strategy Consolandi et al. 2020). Moreover, Eccles \& Klimenko (2019) state that this interest in ESG assets is driven by the growing evidence of the positive impact of ESG materiality on financial performance. Also, the European Banking Authority (EBA) stressed the importance of including ESG information into the regulatory and supervisory framework of EU credit institutions European Banking Authority, 2018. Furthermore, there is a need to improve the measurement and modelling of the impacts of climate change on financial stability in order to underpin a policy debate as highlighted by the European Central Bank (2021). Nevertheless, using ESG factors has made the investment process noticeable more complex Berg \& Lange 2020). While more than 2000 empirical studies have been done analysing ESG factors and financial performance, little is known about the dependence structure and associated risks [Friede, 2019, Shafer \& Szado 2018 Lööf et al. 2021). This is especially important as ESG scores are often linked to investment risk. The EBA defines ESG risks as "the risks of any negative financial impact to the institution stemming, from the current or prospective impacts of ESG factors on its counterparties" (European Banking Authority, 2020. p. 28). While regulators finally acknowledge the role of ESG factors in determining part of a company's risk, no guidelines are provided in how to best capture and quantify such risk. Then, ESG scores should possibly deliver some information on a company's ESG risk and its riskiness as a whole. This also means that companies that have the same ESG rating, 
as explained above, should share similar risk characteristics and properties. Understanding these components is especially important in times of increased volatility as considering the (tail) dependence structure among similarly rated assets is essential in order to set in place effective risk management and diversification strategies Ane \begin{tabular}{|l|l|l|l|l|}
\hline \& Kharoubi 2003 & Frahm et al. 2005 & Malevergne et al. 2005: Berg \& Lange 2020.
\end{tabular}

The contribution of this research is manifold. We propose a R-vine copula ESG risk model to capture the de-

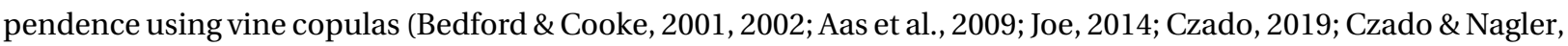
2022) and to identify the systematic and the idiosyncratic risk component considering specific ESG classes of each asset. Inspiration for this model arise from Brechmann \& Czado 2013) who considered sectorial dependencies. This allows us to show, to our knowledge for the first time, that risk can also be linked to an ESG rating classes. Furthermore, it contributes to the understanding of the (tail) dependence structure of various assets belonging to the same ESG rating class and introduces different risk measures that try to capture specific ESG risk and the market risk conditionally on ESG classes. By quantifying the overall and lower tail ESG risk among assets that belong to the same ESG class, we show that these dependencies exist, can be quantified, and are not negligible, especially in times of crisis.

The paper is structured as follows; Section 2 summarizes the literature and creates an understanding of ESG scores and the occurrence of (tail) risk and dependence structures while Section 3 describes the S\&P 500 data used and includes a preliminary risk analysis. Section 4 introduces dependence modelling and vine copulas and then proposes the R-vine copula ESG risk model. Section 5 reports the empirical results. Lastly, Section 6 concludes and provides an outlook for future research.

\section{ESG Scores, Dependence, and Risk}

While ESG scores solely try to capture the amount of positive ESG disclosure of a company, the large influx into ESG investments have brought attention to the risk and return from such investments. It has been shown that ESG factors may impact financial performance by substantiating themselves in "financial or non-financial prudential risks, such as credit, market, operational, liquidity and funding risks" (European Banking Authority 2020 p. 27). According to the EBA, ESG risks are defined to materialize when ESG factors have a negative impact on the financial performance or solvency (European Banking Authority, 2020). Furthermore, it is argued that the materiality of ESG risks depends on the risks posed by ESG factors over different time frames European Banking Authority, 2020. If this is accurate, the ESG scores and ratings should contain information about the company's risk. Even though ESG has mostly been defined in terms of risk by the regulator, and there is an ongoing debate on the effects of using ESG scores on the financial performance research, there is no consensus on the (tail) depen- 
dence structure of assets within and between each ESG rating class. Understanding the (tail) dependence and risk structure of several assets, however, is necessary to access inherent risks in the financial market.

Generally, market returns are assumed to follow a multivariate normal distribution; however, research has shown that this is found to be not accurate in reality, and left tails are often heavier than right tails [Cont 2001 Jondeau \& Rockinger 2003). Therefore, modelling the possibly non-Gaussian dependence among assets and understanding the appearance of joint (tail) risk is especially important for asset pricing and risk management. Tail risk or tail dependence is characterized as the probability of an extremely large negative (positive) return of an asset given that the other asset yields an extremely large negative (positive) return and is commonly quantified by the so-called tail-dependence coefficient (Embrechts et al. 2001: Frahm et al. 2005: Xu \& Li 2009). Tail risk arises when the likelihood of an extreme event that is more than three standard deviations away from the mean is more likely to occur than shown by a normal distribution (Kelly \& Jiang, 2014). Generally, it is accepted that tail dependence can be used as a proxy of systemic risk, and tail risk has been linked to negative consequences for corporate investment and risk-taking [Gormley \& Matsa. 2011: Gormley et al. 2013 Shirvani \& Volchenkov 2019].

Some researchers argue that responsible ESG practices might mitigate the market's perception of a company's tail risk and, therefore, reduce ex-ante expectations of a left-tail event (Shafer \& Szado, 2018). In brief, they state that considering responsible business practices when creating an equity portfolio can act as insurance against left-tail risk (defined as stock price tail risk using the slope of implied volatility) and, with that, protect company value. This is also in line with De \& Clayman 2015) as well as Wamba et al. 2020) who add that especially positive environmental performance can act as insurance for companies, reducing the probability of an adverse event occurring and with that reducing the company's systematic risk. Ashwin Kumar et al. 2016) add that positive ESG practices can make a company "less vulnerable to reputation, political and regulatory risk and thus leading to lower volatility of cash flows and profitability" (p. 292). Furthermore, positive ESG performance may generate more loyalty from customers and employees and, through that, protect companies from unforeseen harmful events, resulting in reduced tail risk (Shafer \& Szado 2018). Besides, better ESG performance allows companies to experience adverse events less often and lose less value if they do occur (Minor.2011. On the other hand, Zhang et al. 2021) extend the work by Shafer \& Szado 2018) by considering implied skewness and find a higher negative tail risk for higher ESG rated companies.

Others recognize that improving ESG performance can also help with risk control and exposure Giese et al. 2019). Maiti 2020 finds that overall portfolios developed using the overall ESG as well as the individual E (Environment), S (Social), and G (Governance) factors generally show better investment performance, implying policy modifications. In contrast, Breedt et al. (2019) show that ESG-tilted portfolios do not necessarily have higher risk- 
adjusted returns. These findings are in line with Lööf et al. (2021) who argue, focusing on the Covid-19 crisis, that higher ESG scores are associated with less downside tail risk but also lower upside potential on returns. Moreover, Sherwood \& Pollard (2017) find that integrating ESG information into the emerging market equity investment of institutional investors can create higher returns and lower downside risks compared to non-ESG equity investments. Other scholars have observed a mitigating effect of ESG performance on stock price crash risk if a company has less effective governance Kim et al. 2014). Hoepner et al. (2016) found supporting evidence on one single institutional investor that ESG engagements can be associated with subsequent reductions in downside risk.

Looking at a country's creditworthiness, Capelle-Blancard et al. (2019) show that countries with above-average ESG scores are linked to reduced default risk, and smaller sovereign bond yield spreads. Additionally, Breuer et al. (2018) state that the cost of equity is reduced when a company invests in CSR, given that it is located in a country with high investor protection. Moreover, Li et al. (2017) find that companies in regions of high social trust tend to have lower tail risk. A possible reason why environmental practices have the power to control tail risk could be that a company's good social records will be more valuable in the long run due to a lower frequency of litigation (Goldreyer \& Diltz 1999). Additionally, higher environmental standards are valuable to shareholders due to companies avoiding litigation costs, reputation losses, and environmental hazards (Chan \& Walter. 2014). Furthermore, ESG can drive an asymmetric return pattern in which socially responsible investment (SRI) funds (using positive rather than negative screenings) outperform conventional funds in times of crisis but underperform in calm periods (Nofsinger \& Varma 2014). Moreover, Bae et al. (2019) find that CSR reduces the costs of high leverage and decreases losses in market share when firms are highly leveraged.

Despite these extensive efforts, the effect of ESG scores on (tail) dependence and (tail) risks has not yet been clearly understood, and literature studying the impact of ESG behaviors on tail risk is still very limited Zhang et al. 2021). While some question whether an ESG-related risk factor that can help to identify superior investments even exists (Cornell [2021), others provide evidence that ESG ratings are subject to a non-diversifiable risk component as the development depends on the overall market (Dorfleitner et al. 2016). Therefore, in order to estimate ESG risk, a closer look the assets within the ESG class and possibly the complete market has to be taken. Investors have been aware of the need to use more sophisticated models to assess the dependence behavior of assets since the financial crisis, however, such models, which allow investors to quantify (tail) dependence and (tail) risk among ESG-based classes of assets, have yet to be introduced. In this paper, we apply vine copulas to model the complex dependence structure and compute different risk measures, including ESG risk, market risk conditionally on ESG class, and an idiosyncratic risk component, which allow to explicitly capture (tail) dependence and possibly aid the investor in their decision-making process. 


\section{The Data}

We consider daily logarithmic return and yearly environmental, social, and governance (ESG) data of 334 US companies $j$, constituents of the S\&P 500 index, for which the yearly ESG scores $\left(E S G_{y, j}\right)$ from Refinitiv ${ }^{1}$, which are ranked based and have values between 0 and 100, are available in the period from 3 January 2006 to 31 December 2018. Refinitiv (2021) allows to attribute the assets into four different rating classes based on their ESG score. Assets are given a D grade for an ESG score lower than 25, C for an ESG score between 25 and lower than 50, B for an ESG score between 50 and lower than 75, and finally A for an ESG score between 75 and 100 . The time period is chosen in order to have the largest possible time period for the largest number of assets to get a comprehensive analysis of assets belonging to the S\&P 500. The overall time frame is split into three different time periods $q$ : $q_{1}=2006-2010, q_{2}=2011-2015$, and $q_{3}=2016-2018$. The first two intervals are made of five years of data each, where the first interval includes the 2008 financial crisis. The last interval consists of three years of data, and their ESG scores are to be considered not definitive according to Refinitiv as they were not yet five years old when downloading the data (in November 2020). This means that the ESG scores can be modified from the provider post-publication. It is, however, not an option for investors to wait until scores are definitive as investment decisions are made daily using all the data available at the time. In order to compute the weighted ESG class indices, which we later need in our R-vine copula ESG risk model, the S\&P 500 market capitalization weights $\left(M_{j}\right)$ from 1 January 2015, as well as the information on the economic sector $S$ for each asset $j$ are downloaded from Refinitiv (2021).

95\% VaR

To get a preliminary understanding if ESG scores can provide additional information on a company's riskiness, the empirical 95\% Value at Risk (VaR), computed as the empirical quantile of the asset return distribution based on daily data for each asset $j$ in the period $q$ grouped according to their mean ESG scores across all sectors $S$ is presented in Figure 1 . The assets are attributed to the four different ESG classes $A, B$, $C$, and $D$ following the thresholds $(25,50,75)$ given by Refinitiv $(2021)$ as explained above. Notice VaR values are smaller and exhibit larger variability during the time period 2006-2010, due to the 2008 financial crisis, while estimates become larger and, therefore, less extreme in the other time periods. It is also quite evident, especially for the time periods 20062010 and 2011-2015, that ESG scores seem to be capable of providing information on the tail risk of an asset, as

\footnotetext{
${ }^{1}$ The ESG scores considered are the ones available from Refinitiv, the financial and risk business unit of Thomas Reuters. Refinitiv offers a comprehensive ESG database across more than 500 different ESG metrics [Refinitiv 2021]. These percentile-ranked ESG scores are designed to measure the company's relative ESG performance, commitment, and effectiveness across ten main topics, including emissions,resource use, and human rights, all of which are based on publicly reported data Refinitiv 2021.
} 
better-rated companies tend to have less negative median VaR values. This does not happen for 2016-2018, where ESG scores are yet not definitive and might possibly be adapted in the future. Nevertheless, differences tend to diminish in the last two periods for classes $A, B$, and $C$ as also companies tend to improve their ESG scores, as shown in Figure 2 Still, ESG class $D$, which typically contain companies that have not yet fully disclosed ESG information and are also lower-rated than other companies, exhibit the worst VaR levels also for the time interval 2016-2018. This is in line with the findings of Sahin et al. (2021) who show that there is no clear relationship with risk measures in the most recent ESG scores.

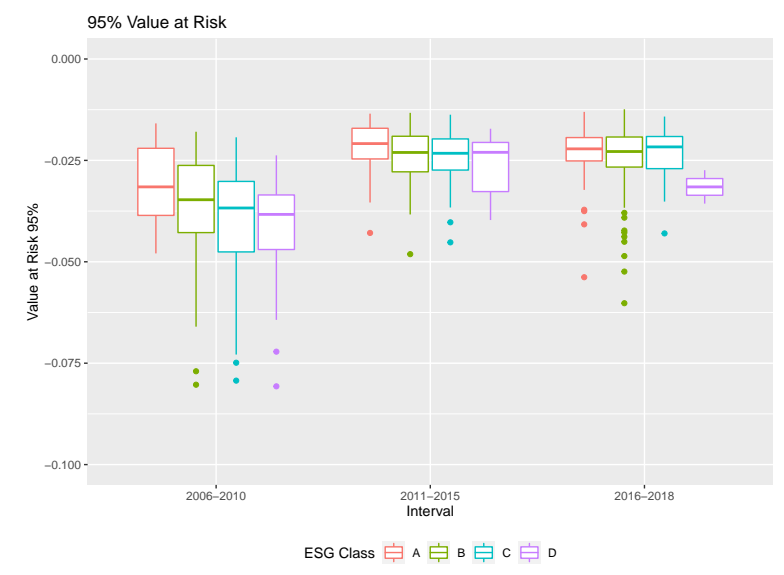

Figure 1: Empirical 95\% Value at Risk classified by ESG class using Refinitiv thresholds and time period $q$.

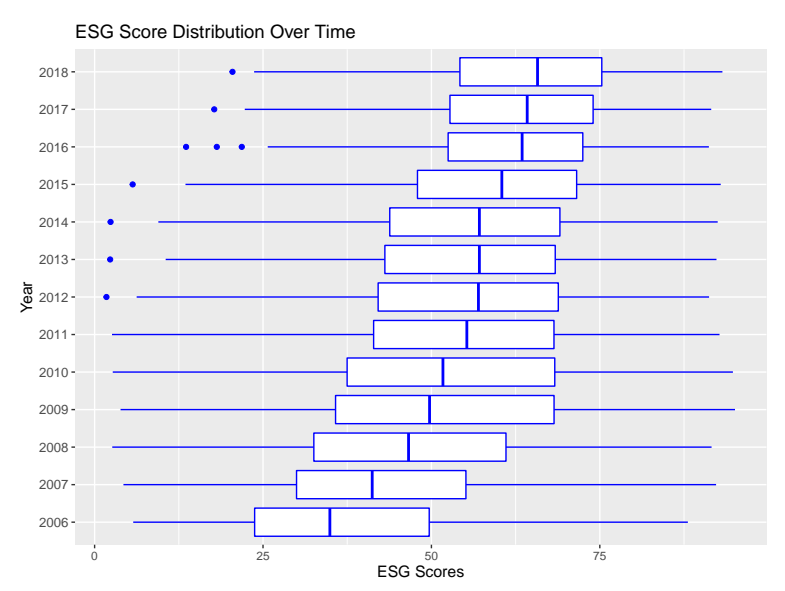

Figure 2: Development of ESG scores over the years.

Summing up, empirical data suggest that ESG scores can provide information on tail riskiness of companies and allow to group assets that might share similar tail-risk characteristics, at least in the first two time periods. Plots for 99\% VaR and 95\% and 99\% Expected Shortfall show similar behaviour and are available upon request.

\section{R-Vine Copula ESG Risk Model and Methodology}

In general, a distributions rarely follows the strict spherical and elliptical assumptions as implied by correlation (Embrechts et al. 2002). Therefore, according to Embrechts et al. (2002), this traditional dependence measure is often not suited to create a proper understanding of the dependence in financial markets or fully comprehend the risk in extreme events. While Pearson correlation has been used as a measure of pairwise dependence, modern risk management requires a thorough stochastic understanding beyond linear correlation. As ESG risk is possible non-diversifiable (see Dorfleitner et al. (2016)), and the European Banking Authority (2020) argues that ESG risk is 
supposed to manifest also in market risk, it takes a more complex risk measure to estimate its magnitude. This is where copula modeling steps in.

A copula $C$ is a cumulative distribution function (cdf) with univariate uniform marginal distributions on the unit interval. The copula approach is especially popular due to Sklar's theorem (1959), which allows to model the marginal distribution and the dependence separately. Therefore, if $F$ is a continuous $d$-dimensional distribution function of $\mathbf{X}=\left(X_{1}, \ldots, X_{d}\right)^{\top}$ with univariate cdf $F_{p}\left(x_{p}\right)$ of a continuous random variable $X_{p}$ for $p=1, \ldots, d$ with its realizations $x_{p}$, the joint distribution function $F$ can be written as

$$
F\left(x_{1}, \ldots, x_{d}\right)=C\left(F_{1}\left(x_{1}\right), \ldots, F_{d}\left(x_{d}\right)\right) .
$$

The corresponding density is

$$
f\left(x_{1}, \ldots, x_{d}\right)=c\left(F_{1}\left(x_{1}\right), \ldots, F_{d}\left(x_{d}\right)\right) \cdot \prod_{p=1}^{d} f_{p}\left(x_{p}\right)
$$

where $c$ is the $d$-dimensional copula density of the random vector $\mathbf{F}=\left(F_{1}\left(X_{1}\right), \ldots, F_{d}\left(X_{D}\right)\right)^{\top} \in[0,1]^{d}$ and $f_{p}\left(x_{p}\right)$ is the associated univariate marginal density of $F_{p}\left(x_{p}\right)$ for $p=1, \ldots, d$.

Different copula types with their reflections and rotations can accommodate flexible dependence patterns in the bivariate case $(d=2)$, as shown in the Appendix in Table C.5. Nevertheless, the existing parametric families of multivariate copulas are not as flexible as the bivariate copula families to represent complex dependence patterns. For instance, the multivariate Gaussian copula does not accommodate any tail dependence and has been strongly criticized after the 2008 financial crisis (Li. 2000|Salmon. 2012 2 Puccetti \& Scherer. 2018 Czado 2019). The multivariate Student's t copula allows for tail dependence but does not capture any asymmetry in the tails. Furthermore, multivariate exchangeable Archimedean copulas become inflexible as the dimension increases since they model the dependence between a large number of pairs of variables using not more than two parameters. If no dependence is found, and the random variables are independent, the independence copula best models their behavior.

In order to improve the copula method with regard to larger dimensions and to accommodate a great variety of dependence structures, vine copulas (so-called pair copula constructions) use conditioning and were made operational for data analysis by Aas et al. (2009). They are a class of copulas, which are based on the conditioning ideas first proposed by Joe (1996) and further developed by Bedford \& Cooke (2001 2002). The approach allows to construct any $d$-dimensional copula and its density by $\frac{d \cdot(d-1)}{2}$ bivariate copulas and their densities. Furthermore, the expression can be represented by an undirected graphical structure involving a set of linked trees, i.e., a regular 
(R-) vine structure (Bedford \& Cooke 2001). An example is given in Figure 3 and more details on R-vines and vine trees are given by Kurowicka \& Cooke (2006); Kurowicka \& Joe (2011); Joe (2014); and Czado (2019).

In previous works, copulas and vines copulas have had various financial applications. Some examples include but are not limited to: Bhatti \& Nguyen (2012) who applied time-varying copulas to capture the tail dependence between selected international stock and Nguyen \& Bhatti (2012) who used non-parametric and parametric copulas to capture the dependence between oil prices and stock markets. Furthermore, Naifar (2012) modeled the dependence structure between risk premium, equity return, and volatility in the presence of jump-risk, and Brechmann \& Czado (2013) analysed the sectorial dependence of Euro Stoxx 50. Morover, Fenech et al. (2015) discussed loan default correlation using an Archimedean copula approach, and Pourkhanali et al. (2016) used vine copulas to estimate systemic risk by looking at the connection of financial institutions. Recently, Fink et al. (2017) and BenSaïda (2018) introduced the regime-switching vine copula approach, and Abakah et al. (2021) re-examined international bond market dependence.

\section{R-Vine Copula ESG Risk Model}

In this research, we apply a R-vine copula model to estimate different dependence structures among assets given their ESG classes in order to compute different risk measures. To be able to capture the ESG risk and market risk conditionally on the ESG class of an asset $j$, the proposed first five vine tree structures are defined as shown in Figure 3 In the first vine tree $T_{1}$ in Figure 3 we connect the assets $j$ (abbreviated by $\left.a_{1}, \cdots, a_{87}, b_{1}, \cdots, b_{85}, c_{1}, \cdots, c_{84}, d_{1}, \cdots, d_{78}\right)$ to their belonging ESG class index $\left(I_{t, k}^{q}\right.$ abbreviated by $\left.k \in\{A, B, C, D\}\right)$ and market index ( $M_{t}^{q}$ abbreviated by $M$ ) in period $q$. This allows us to compute the dependence of an asset $j$ with its ESG class, later we use this to compute its ESG risk in Equation 3. In $T_{2}$, in Figure 3 we connect the nodes so that they allow us to compute the market risk conditionally on the ESG class (see Equation 4) following the sequential ESG class order. We then continue to fix $T_{3}$ to $T_{5}$ to be able to compute our risk measures as a fraction of all dependence, positive and negative, an asset has with all ESG classes $k$. In $T_{3}$ in Figure 3 we choose to connect the nodes so that we separate the best and lowest ESG performance from the middle ESG performance, classes $B$ and $C$. By defining $T_{4}$ and $T_{5}$ further, we guarantee that in our risk measures in Section 4 only dependencies with the different ESG class indices $I_{t, k}^{q}$ are included, which is not yet modelled in $T_{1}, T_{2}$, and $T_{3}$. This ensures that the ESG risk is not an individual measure and takes into account complex market movements and dependencies with other ESG classes $k$. 

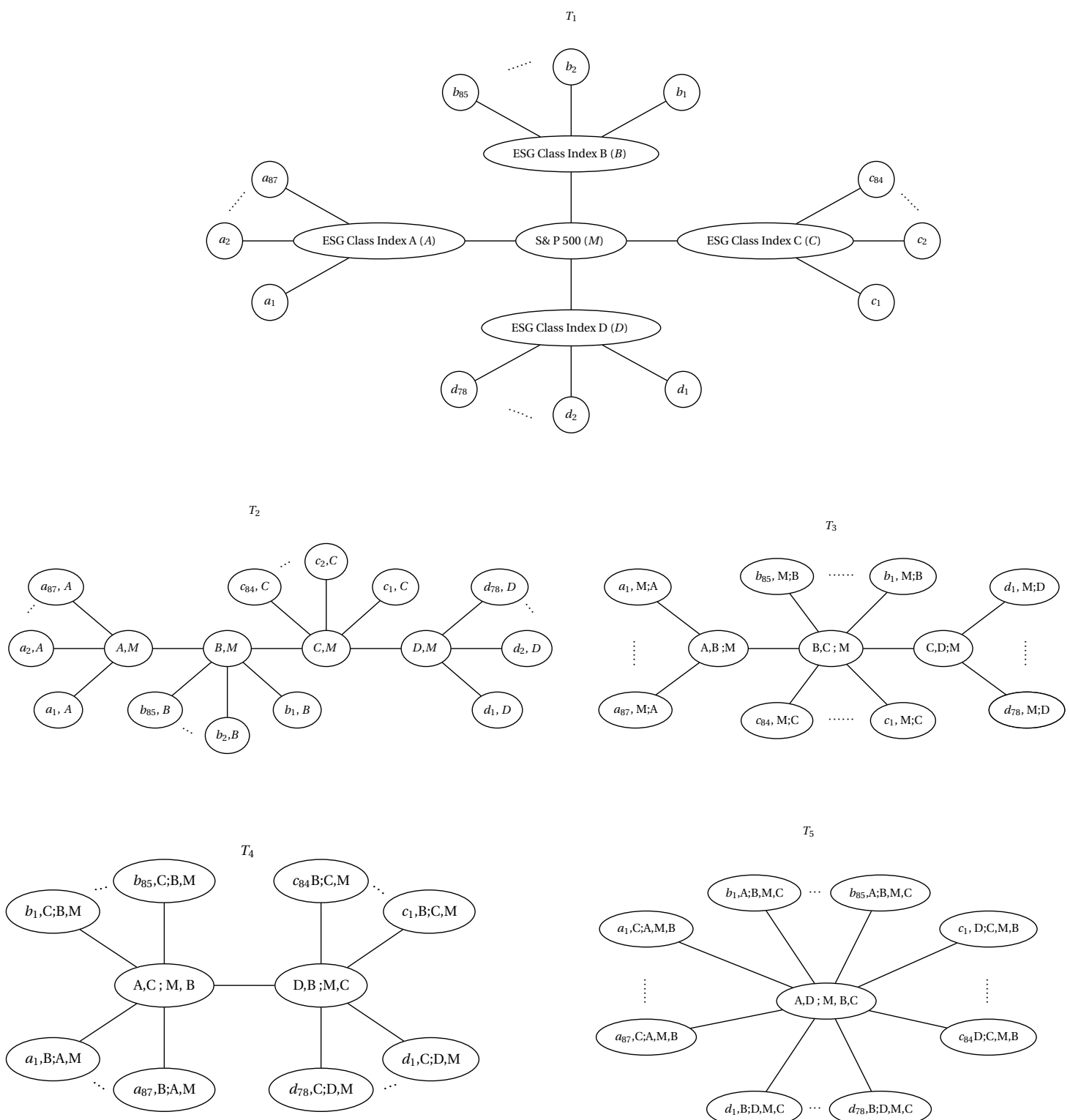

Figure 3: The first five vine trees of the regular vine used.

\section{Inputs for the R-Vine Copula ESG Risk Model}

In order to be able to fit the R-vine copula ESG risk model with the five specified vine trees, the inputs have to be computed. We start by computing the mean ESG score $\left(\overline{E S G}_{j}^{q}\right)$ for each asset $j$ for each time period $q$. We then divide the assets into their ten different economic sectors and rank them according to their $\overline{E S G}_{j}^{q}$. This allows us to group the assets within each sector into four different quartiles according to their ESG performance. Within each sector, we categorize assets with the highest scores in the first quartile as ESG class $A$, assets with the second to highest scores in the second quartile as ESG class $B$, assets with the second to lowest scores in the third 
quartile, as ESG class $C$, and finally, assets with the lowest scores in the fourth quartile, as ESG class $D$ (for details see Appendix A.2 and Appendix A.3.

We define the ESG class quartiles as $k \in(A, B, C, D)$. We choose to rank the assets within their economic sector instead of overall as it has been shown by Ashwin Kumar et al. 2016) that ESG scores affect various sectors to a different degree. Furthermore, we know that ESG scores values are weighted differently within economic sectors (Refinitiv 2021). Therefore, categorizing the assets within their sector allows us to take into account these differences. More importantly, it also allows us to later compute the ESG risk measures that are comparable across sectors. As it has been shown that that investors cannot eliminate ESG risk fully through diversification (see Dorfleitner et al. (2016)), it is not sufficient to compute the risk on an individual level without taking a look at the surrounding assets. We choose to use quartiles instead of Reuters's thresholds to avoid low numerosity in some classes. We now combine all assets according to their ESG class quartile $k$. This means that each ESG rating class $k$ includes assets from all ten different sectors. Overall, ESG class $A$ includes 87 assets, ESG class $B$ includes 85 assets, ESG class $C$ includes 84 assets, and finally ESG Class $D$ includes 78 assets.

Next, we compute the ESG class indices per ESG class $k\left(I_{t, k}^{q}\right.$, i.e. the ESG class index $A$ in period $q$ on trading day $t$ is $\left.I_{t, A}^{q}\right)$ by linearly combining asset returns $\left(Y_{t, j, k}^{q}\right.$ defined as the return of an asset $j$ in period $q$ on trading day $t$ belonging to ESG class $k$ ) in the same mean ESG class $\left(K_{j}^{S, q}\right)$ using the market capitalization weights. As shown in Figure 3 we use only the variable names such as $M$ (Market), $A$ (ESG class index), $a_{1}$ (asset) etc. to denote the nodes. The associated daily data is given by $I_{M, t}^{q}, I_{t, A}^{q}, Y_{t, 1, A}^{q}$ and a full table of notation can be found in Appendix A.1

Then, we use the two step inference for margins approach, proposed by Joe \& Xu (1996), to compute our pseudo-copula data which serves as the input for our R-vine copula ESG risk model (for details see Appendix B) and allows us to estimate the copula parameters of the chosen bivariate copula family (for details see Appendix C.

Additionally, when fitting the R-vine copula ESG risk model, we can specify different bivariate copula families for the pairs of variables. In the first specification, we allow only for the bivariate itau copulas, for which the estimation by Kendall's $\tau$ inversion is available (Student's t, Frank, Gaussian, Clayton, Joe, Gumbel, and Independence copula). Using these, we also allow for asymmetry in the upper and lower tails, as shown in Table C.5 in the Appendix. These copula families have a one-to-one relationship between their copula parameter and Kendall's $\tau$. In the second specification, we include additional copula families with two parameters such as BB1 (a combination between both extreme cases of Clayton copula and Gumbel copula), BB7 (a combination of Joe copula and Clayton copula), and the extreme-value copula BB8 (extended Joe) in order to see if this improves our model fit. 
Lastly, we fit a specification using only Gaussian copulas to see the change in model fit if we do not account for the dependence in the extremes. To choose our optimal bivariate copula family specification, we use the modified Bayesian Information Criteria (mBIC) instead of the widely used Bayesian Information Criteria (BIC) by (Schwarz 1978. The mBIC has been proposed by Nagler et al. 2019) and is tailored to sparse vine copula models in highdimensions. These scholars show that the mBIC can consistently distinguish between the true and alternative models. We then continue our analysis using the best fitting model only.

\section{R-Vine Risk Measures}

After computing the inputs for the R-vine copula ESG risk model, estimating the pseudo-copula data, and fitting it to our model with the specified five vine trees, we can compute three different risk measures using the overall dependence $(\tau)$ and lower (tail) dependence $(\lambda)$. We introduce an overall ESG risk $R_{j_{k}^{q}}^{E S G}(\tau)$ and lower tail ESG risk $R_{j_{k}^{q}}^{E S G}(\lambda)$, which we can compute for each asset $j$ with its ESG class $k$ in period $q$. It accounts for the ESG risk of an asset $j$ belonging to a specific ESG class $k$ and gives the fraction of all dependence, positive and negative, explained by the assets ESG class. Additionally, we estimate the market risk conditionally on the ESG class for each asset $j$ as $R_{j_{k}^{q}}^{\text {Market }}(\tau)$ and $R_{j_{k}^{q}}^{\text {Market }}(\lambda)$ with all the (tail) dependence on the ESG class being removed. Lastly, by subtracting both indicators from 1 , we can get the overall idiosyncratic risk $R_{j_{k}^{q}}^{i d i o}(\tau)$ and lower tail idiosyncratic risk as $R_{j_{k}^{q}}^{i d i o}(\lambda)$ for each asset $j$ within each time period $q$. See Brechmann \& Czado 2013 for sectorial estimation.

We choose the empirical Kendall's $\tau$ and its estimate $\hat{\tau}$, whose values range from $[-1,1]$ (Joe 2014), as our dependence measure for the overall risk measures ${ }^{2}: R_{j_{k}^{q}}^{E S G}(\tau), R_{j_{k}^{q}}^{\text {Market }}(\tau)$, and $R_{j_{k}^{q}}^{i d i o}(\tau)$. To exclude unrealistic assumptions, we assume that asset $j$ is not independent of all other assets and include all Kendall's $\tau$ only in absolute value. Similarly, we can also define these risk measures using the lower tail dependence coefficient ${ }^{3}$ as $: R_{j_{k}^{q}}^{E S G}(\lambda), R_{j_{k}^{q}}^{\text {Market }}(\lambda)$, and $R_{j_{k}^{q}}^{i d i o}(\lambda)$. By using the lower tail dependence coefficient as the input value, these risk measures quantify the strength of the dependence within the lower-left-quadrant tail of an assets return and its associated ESG class index in relation to all other assets within the fitted R-vine copula ESG risk model. The values for the risk measures are in the interval $[0,1]$. As the equations are identical apart from dependence measure $\tau$ or

\footnotetext{
${ }^{2}$ Kendall's $\tau$ is a ranked based dependence measure robust to outliers that fits the aim of our analysis and can be defined in terms of copulas for two continuous random variables $\left(X_{1}, X_{2}\right)$ with copula $C$ as $\tau=4 \int C\left(u_{1}, u_{2}\right) d C\left(u_{1}, u_{2}\right)-1$. An alternative overall weight measure could be Spearman's $\rho$.$$
[0,1]^{2}
$$

${ }^{3}$ When Student's t and Clayton (and BB1 and BB7) copulas are chosen as best fit among the bivariate copula families given in Table C.5 we can use this information to also estimate the lower tail dependence coefficient $\lambda$ which ranges from $[0,1]$ and is defined for a bivariate distribution with copula $C$ as $\lambda^{\text {lower }}=\lim _{x \rightarrow 0^{+}} P\left(X_{2} \leq F_{2}^{-1}(t) \mid X_{1} \leq F_{1}^{-1}(t)\right)=\lim _{x \rightarrow 0^{+}} \frac{C(t, t)}{t}$. The lower tail dependence coefficient is also non-zero when the fitted bivariate copula class is Student's $t$, Clayton, $180^{\circ}$ Joe, $180^{\circ}$ Gumbel, BB1, BB7, or $180^{\circ}$ BB8 in our model. For other bivariate copula families, we have zero lower tail dependence coefficient. Other methods could include estimating a specific distribution or a family of distributions; or working with a non-parametric model. We refer to Frahm et al. 2005] for further reading on estimation methods.
} 
$\lambda$, only the overall risk measures are presented below. For simplification, we drop the sector index $S$ in the notation of the risk measures for each asset $j$.

\section{Overall ESG Risk}

For each asset of ESG Class $A$ in period $q$, i.e. $j_{A}^{q} \in\left\{j \mid K_{j}^{S, q}=A\right.$ for $q=1,2,3$ and $\left.S=1, \cdots, 10\right\}$ and $q=1,2,3$ :

$$
R_{j_{A}^{q}}^{E S G}(\tau)=\frac{\left|\hat{\tau}_{j_{A}}^{q}, I_{A}^{q}\right|}{\left|\hat{\tau}_{j_{A}^{q}}^{q}, I_{A}^{q}\right|+\left|\hat{\tau}_{j_{A}}^{q}, I_{M}^{q}\right| I_{A}^{q}|+| \hat{\tau}_{j_{A}}^{q}, I_{B}^{q}\left|I_{A}^{q}, I_{M}^{q}\right|+\left|\hat{\tau}_{j_{A}}^{q}, I_{C}^{q}\right| I_{A}^{q}, I_{M}^{q}, I_{B}^{q}|+| \hat{\tau}_{j_{A}}^{q}, I_{D}^{q}\left|I_{A}^{q}, I_{M}^{q}, I_{B}^{q}, I_{C}^{q}\right|} .
$$

$R_{j_{B}^{q}}^{E S G}(\tau), R_{j_{C}^{q}}^{E S G}(\tau)$, and $R_{j_{D}^{q}}^{E S G}(\tau)$ can be derived similarly.

\section{Overall Market Risk conditionally on ESG Class}

For each asset of ESG Class $A$ in period $q$, i.e. $j_{A}^{q} \in\left\{j \mid K_{j}^{S, q}=A\right.$ for $q=1,2,3$ and $\left.S=1, \cdots, 10\right\}$ and $q=1,2,3$ :

$$
R_{j_{A}^{q}}^{\text {Market }}(\tau)=\frac{\left|\hat{\tau}_{j_{A}^{q}}^{q}, I_{M}^{q}\right| I_{A}^{q} \mid}{\left|\hat{\tau}_{j_{A}}^{q}, I_{A}^{q}\right|+\left|\hat{\tau}_{j_{A}}^{q}, I_{M}^{q}\right| I_{A}^{q}|+| \hat{\tau}_{j_{A}}^{q}, I_{B}^{q}\left|I_{A}^{q}, I_{M}^{q}\right|+\left|\hat{\tau}_{j_{A}}^{q}, I_{C}^{q}\right| I_{A}^{q}, I_{M}^{q}, I_{B}^{q}|+| \hat{\tau}_{j_{A}}^{q}, I_{D}^{q}\left|I_{A}^{q}, I_{M}^{q}, I_{B}^{q}, I_{C}^{q}\right|} .
$$

$R_{j_{B}^{q}}^{\text {Market }}(\tau), R_{j_{C}^{q}}^{\text {Market }}(\tau)$, and $R_{j_{D}^{q}}^{\text {Market }}(\tau)$ can be derived similarly.

\section{Overall Idiosyncratic Risk}

For each asset of ESG Class $A$ in period $q$, i.e. $j_{A}^{q} \in\left\{j \mid K_{j}^{S, q}=A\right.$ for $q=1,2,3$ and $\left.S=1, \cdots, 10\right\}$ and $q=1,2,3$ :

$$
R_{j_{A}^{q}}^{i d i o}(\tau)=1-R_{j_{A}^{q}}^{E S G}(\tau)-R_{j_{A}^{q}}^{\text {Market }}(\tau)
$$

$R_{j_{B}^{q}}^{i d i o}(\tau), R_{j_{C}^{q}}^{i d i o}(\tau)$ and $R_{j_{D}^{q}}^{i d i o}(\tau)$ can be derived similarly.

Summing up, fitting the R-vine copula ESG risk model enables us to capture complex dependence structures as it allows us to account for asymmetric and tail dependence. Moreover, to get a more comprehensive understanding of the overall share of dependence an asset has with other assets within the same ESG class given all other assets, these (tail) risk measures are standardized as ratios instead of single dependence measures of an asset $j$ with its ESG class index alone. This helps to understand if there are common behaviors - especially for tail dependence. Common dependencies could indicate that a time series (e.g., returns) exhibit co-movements and, therefore, could share some risk properties. As many investors tilt their portfolio towards comparable large ESG score, using an inclusion or exclusion approach, understanding the dependence between similarly ESG rated assets is necessary in order to be able to capture co-movements and promote diversification. 


\section{Empirical Results}

After fitting the R-vine copula ESG risk model for three copula family specifications (itau, parametric, Gaussian), we find that according to the mBIC, the R-vine copula ESG risk model with the itau copula family specification best fits our model and allows to most optimally estimate the dependencies between the assets for all three time periods $q$. We also notice that the Gaussian R-vine copula ESG risk model always performs worst. Also, when looking at which of the copula families are fitted most often within each specification, we find that not very often the Gaussian copula is chosen for the itau and parametric R-vine copula ESG risk model. This is especially true for the first vine tree $T_{1}$ which models the dependence of an asset with its ESG class. As the Gaussian copula does not capture any tail dependence, and often the Student's t copula is chosen, these results indicate that the assets definitely share some tail dependence. Thus, the Gaussian R-vine copula ESG risk model does not fully comprehend the risk in extreme events. In our analysis, we therefore use the itau R-vine copula ESG risk model to estimate our risk measures. For more details, the information criteria for all three models in each time period $q$ are given in the Appendix D.1 and the specific number of copula families fitted in the first vine tree $T_{1}$ are given in Appendix D.2 while all other vine trees are available upon author request.

In Figure 4 and Table 1 focusing on overall ESG risk we find that assets that belong to ESG class $D$ perform the worst, as they experience the highest overall ESG risk in calm periods (2011-2015, 2016-2018). This is in line with the literature, as Shafer \& Szado 2018) argue that strong ESG practices can act as insurance against left-tail events as well as others who find that superior ESG performance reduces volatility Albuquerque et al. 2020 Bouslah et al. 2018). In contrast to other scholars who found that ESG performance mitigates financial risk during crisis using Chinese companies and the Covid-19 crisis Broadstock et al. (2021), we find that in times of the financial crisis 2006-2010, especially assets belonging to a $B$ ESG class tend to have the lowest overall ESG risk. Assets belonging to ESG class $A$ show unexpected worse overall ESG risk, possibly because of a high investment volume and popularity from investors who wrongly believe that ESG performance can make them resilient in times of crisis. These findings are in line with Demers et al. (2021) who argue that ESG scores did not immunize stocks during the COVID-19 crisis and did, therefore, not protect the investors from unexpected losses. Furthermore, Flori et al. (2021), who look at bipartite network representation of the relationships between mutual funds and portfolio holdings, find that the popularity of assets does not necessarily yield a beneficial outcome. This shows that portfolios which invest in less popular assets generally outperform those investing in more popular ones. Especially in the most recent time period, we find a larger variability of overall ESG risk belonging to the different classes. All standard deviation values can be found in Appendix E.1 Companies that are not best or worst performers, i.e. assets in ESG classes $B$ and $C$, show the lowest overall ESG risk. Again, this could be due to the 
non-popularity of assets with mediocre ESG performance, as many investment strategies focus on inclusion or exclusion approaches. We also have to keep in mind that the ESG scores are not yet definitive; therefore, they could still be changed and adapted to change the ESG risk behaviour.

When looking at the overall market risk conditionally on the ESG class, we find it to be relatively low for all assets. The difference among ESG classes also diminishes in times of calm and in the most recent period. Nevertheless, in times of crisis, 2006-2010, assets in the ESG class $A$ seem to carry the least market risk, which is in line with the literature as ESG practices have been connected to better governance and possible reduction in risk exposure.

Finally, the overall idiosyncratic component of the assets varies again throughout the time periods. In times of crisis, companies with good ESG performance show lower overall idiosyncratic risks, while companies with a lower ESG score show worse risks. This is in line with the recent literature, as Becchetti et al. (2015) show that ESG investing reduces the idiosyncratic volatility exposure. This behaviour changes when looking at times of calm in 2011-2015 and the most recent period. Here companies that either have very high or very low ESG scores indicate the lowest idiosyncratic risk. However, this does not necessarily mean that including the extremes in a portfolio results in the best possible performance as Campbell et al. (2001) and Luo \& Bhattacharya (2009) have shown that the realized performance in portfolios depends on the overlapping effects of systematic and idiosyncratic risks.

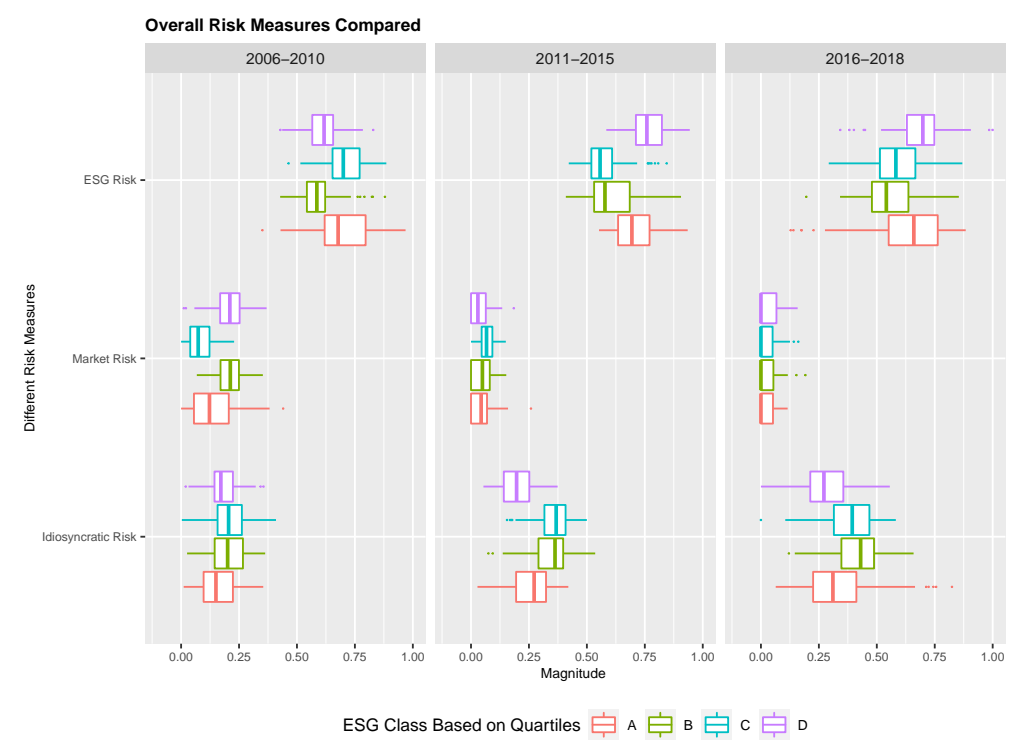

Figure 4: Overall ESG risk measures for each time interval $q$ using quartiles for ESG classes. 


\begin{tabular}{c|cccc|cccc|ccccc}
\hline Type of Risk & \multicolumn{4}{|c|}{ ESG Risk } & \multicolumn{5}{c|}{ Market Risk } & \multicolumn{5}{c}{ Idiosyncratic Risk } \\
\hline Year & A & B & C & D & A & B & C & D & A & B & C & D \\
\hline $2006-2010$ & 0.696 & 0.589 & 0.706 & 0.614 & 0.138 & 0.205 & 0.083 & 0.207 & 0.166 & 0.206 & 0.211 & 0.179 \\
$2011-2015$ & 0.704 & 0.611 & 0.577 & 0.766 & 0.044 & 0.052 & 0.066 & 0.039 & 0.252 & 0.338 & 0.357 & 0.195 \\
$2016-2018$ & 0.630 & 0.564 & 0.595 & 0.693 & 0.027 & 0.029 & 0.027 & 0.030 & 0.343 & 0.407 & 0.378 & 0.276 \\
\hline
\end{tabular}

Table 1: Mean values for overall ESG Risk, Market Risk and Idiosyncratic Risk for each ESG Class $k$ in time interval $q$.

When looking at the lower tail risk measures in Figure 5 and Table 2, using the estimated lower tail dependence coefficient $(\lambda)$, we first notice that the magnitude is close to 1 . This is due to the design of the indicator and the number of copula families with zero tail dependence coefficients. Nevertheless, we can still compare the risk measures across ESG classes and time periods. The intuition why companies with high ESG scores could potentially encounter lower downside risks is that it is common believe that socially responsible companies are less exposed to company-specific events that negatively impact the equity price (Diemont et al. 2016). Using questionnaires and annual assessments, some scholars already found a significant relationship between certain aspects of CSR and downside tail risk which differs when looking at the region and time [Diemont et al. 2016.

We find that assets with ESG class $A$ show the most favourable lower tail ESG risk throughout the first two time periods. However, the difference diminishes in 2011-2015 and changes in the most recent period. While some scholars argue that ESG tail risk has become more pronounced in the most recent year using the Covid-19 crisis Lööf et al. 2021), our findings show that the risk measures are very volatile in the most recent period (see also all standard deviation values in Appendix E.1. From our data provider, we know that these ESG scores are not yet definitive and can be updated as analysed by Berg et al. (2021), making the behavior in the last period subject to change.

Looking at the lower tail market risk conditionally on ESG classes, we find that it is very close to 0 . The extreme ESG classes, $A$ and $D$, show an increased risk in the first time period; however, the magnitude is still close to 0 . Again, we find large variability in the last period, which is possibly due to the non-definitive ESG scores. Lastly, the idiosyncratic component for lower tail risk events is very small but still seem to be highest for ESG class $A$ in 2011-2015. The variability again seems to be highest in the most recent period. 


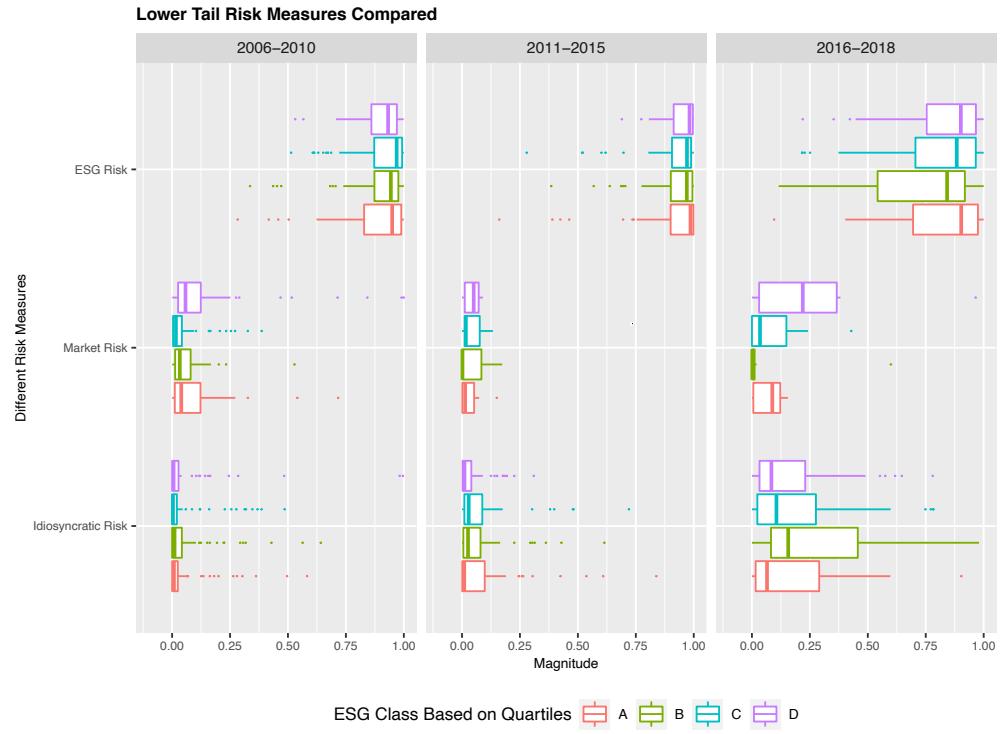

Figure 5: Lower tail ESG risk measures (without 0s and 1s) for each time interval $q$ using quartiles for ESG classes.

\begin{tabular}{c|cccc|cccc|ccccc}
\hline Type of Risk & \multicolumn{4}{|c|}{ Lower Tail ESG Risk } & \multicolumn{4}{c|}{ Lower Tail Market Risk } & \multicolumn{5}{c}{ Lower Tail Idiosyncratic Risk } \\
\hline Year & A & B & C & D & A & B & C & D & A & B & C & D \\
\hline $2006-2010$ & 0.881 & 0.902 & 0.898 & 0.897 & 0.084 & 0.053 & 0.054 & 0.079 & 0.035 & 0.045 & 0.048 & 0.024 \\
$2011-2015$ & 0.911 & 0.881 & 0.937 & 0.927 & 0.035 & 0.049 & 0.028 & 0.044 & 0.054 & 0.070 & 0.036 & 0.029 \\
$2016-2018$ & 0.768 & 0.638 & 0.816 & 0.729 & 0.072 & 0.087 & 0.093 & 0.110 & 0.159 & 0.274 & 0.090 & 0.161 \\
\hline
\end{tabular}

Table 2: Mean values for lower tail ESG risk, Market Risk and Idiosyncratic Risk for each ESG Class $k$ in time interval $q$.

\section{Conclusion}

Starting from an empirical analysis of real-world financial data, we notice that ESG rating classes can provide information on overall risk and tail risk. In fact, as Figure 1 shows, especially in the time periods 2006-2010 and 2011-2015, assets with better ESG ratings seem to exhibit less tail risk. However, as companies tend to improve their rating throughout time, as seen in Figure 2 these differences tend to diminish, especially in the interval 20162018, in which, however, Refinitiv ESG scores cannot yet be considered definitive. Based on such observations, we propose the R-vine copula ESG risk model to capture (tail) dependence and compute three new risk measures both for overall and lower tail risk.

Using vine copula models allows us to capture financial times series characteristics including non-symmetry and dependence in the extremes, as it can rely on a pair copula construction. Especially the proposed R-vine copula ESG risk model is able to flexibly model the dependence structures using the ESG scores. Moreover, as for 
each level an arbitrary bivariate copula can be specified, every complex dependence structure can be captured effectively and optimally. After estimating the R-vine copula ESG risk model, we cannot only estimate all the conditional dependencies among assets as well as specify their interactions as modelled by different copulas families, but we can also introduce three ESG risk measures that capture ESG risk, market risk conditionally on the ESG class, as well as an idiosyncratic risk component. We notice that in times of calm, assets with a $D$ score show the highest individual ESG risk and tail ESG risk, however, we do not confirm this finding in times of crisis. Assets belonging to ESG class $A$ show unexpected worse ESG risk in times of calm, possibly because of a high investment volume and popularity from investors who wrongly believe that ESG performance can make them resilient in times of crisis. We also find a lot of variability in the risk measures in the last years, when the ESG scores are not definitive and can still be changed. Companies that are not best or worst performers, leaving assets in ESG Class $B$ and $C$, often show the lowest ESG risk. Again, this could be due to the non-popularity of assets with mediocre ESG performance.

The understanding and estimation of such dependencies and risks is of utmost importance for setting up adequate risk management and mitigation tools as well as building portfolios, ideally, also ESG diversified and resilient to crises. Current popular ESG inclusion approaches that focus on picking only assets in the highest ESG rating classes could have indeed possibly benefited in the past from better VaR values but such behavior is not clear for the most recent interval, where ESG classes are overlapping and differences are diminishing. In fact, picking assets with the highest ESG scores does not lead to better VaR values necessarily and could result in applying too much pressure on a specific set of assets without a clear benefit. The constant trend in improving ESG scores, as shown in Figure 2 might be a factor behind the lack of VaR differentiation between the classes $A, B$, and $C$ as well as the large variability in the ESG risk in the last time interval, joint to the fact that such ESG scores are not yet definitive. Still, we notice that ESG class $D$ assets tend to exhibit poorer VaR values than other ESG classes and especially in times of calm, exhibit the large overall and lower tail ESG risk, as such classes mostly include assets which have yet to disclose information needed for ESG score computation. This suggests that ESG disclosure might also have some indirect and positive effect on the company risk management. High on the agenda, the current model could be used to develop new ESG investment strategies and ESG based risk mitigation and management modelling tools. 


\section{Appendix A. Notation and Computation}

\section{Appendix A.1. Data}

We introduce the mathematical indices, data sets and their notations used in the paper.

\begin{tabular}{l|c}
\hline Type of Data & Notation \\
\hline Economics Sector & $\mathrm{S}=1, \ldots, 10$ \\
Trading day & $t=1, \ldots, 3271$ \\
Year & $y=2006, \ldots, 2018$ \\
Period & $q=1,2,3$ \\
ESG class Quartiles & $k \in\{A, B, C, D\}$ \\
\hline ESG score of asset $j$ in year $y$ & $E S G_{y, j}$ \\
Log return of asset $j$ on trading day $t$ & $Y_{t, j}$ \\
Log return of asset $j$ in period $q$ on trading day $t$ & $Y_{t, j, k}^{q}$ \\
belonging to ESG class $k$ & $I_{t, M}^{q}$ \\
S\&P 500 log return on trading day $t$ in period $q$ & $M_{j}$ \\
Market capitalization weight of asset $j$ (by 1.01.2015) & $\frac{E S G}{j}$ \\
\hline Mean ESG score of asset $j$ and period $q$ & $K_{j}^{S, q}$ \\
ESG class of asset $j$ and period $q$ per sector $S$ & $\alpha_{j}^{q}$ \\
ESG class weight of asset $j$ in period $q$ & $I_{t, k}^{q}$ \\
Values of ESG class $k$ and period $q$ at trading day $t$ & \\
\hline
\end{tabular}

Table A.3: Mathematical Indices, datasets, and their notation used in the paper.

As mentioned in Section 3 we worked with the mean ESG score and the corresponding ESG class of an asset $j$ for period $q$. Accordingly, we calculated the assets' ESG class weights, which were then used to calculate their corresponding ESG class values, as defined in Table A.3. Their computations are given as follows.

Appendix A.2. Mean ESG score of asset $j$ and period $q\left(\overline{E S G}_{j}^{q}\right)$ :

$$
\overline{E S G}_{j}^{q}=\frac{1}{\left|P_{q}\right|} \sum_{y \in P_{q}} E S G_{y, j} \text { for } \quad \forall_{j, q},
$$

where $P_{1}=[2006,2010], P_{2}=[2011,2015], P_{3}=[2016,2018]$, and $\left|P_{q}\right|$ denotes the number of years in $P_{q}$.

Appendix A.3. Define ESG classes for each asset $j$ within sector $S$ and period $q$ using quartiles $\left(K_{j}^{S, q}\right)$ :

Assume $j^{S, q}$ contains asset $j$ in sector $S$ and period $q$ based on their mean ESG scores $\overline{E S G}_{j}^{q}$, so that the assets are ordered non-decreasingly. To simplify notation we remove the indices $S$ and $q$ from the asset e.g., $l_{1}=l_{1}^{S, q} \cdot n_{s}$ 
is defined as the total number of assets with in each sector $S$. Then, we define the ESG quartiles for Sector $S$ in period $q$ as follows:

We have $\forall j, S, q$ :

$$
\begin{aligned}
& j^{S, q}=\left\{l_{1}, \cdots, l_{n_{s}}\right\} \\
& D^{S, q}=\left\{l_{1}, \cdots, l_{n_{D_{s}}}\right\}, \quad \text { where } \quad n_{D_{s}}=\operatorname{int}\left(\frac{n_{s}}{4}\right)
\end{aligned}
$$

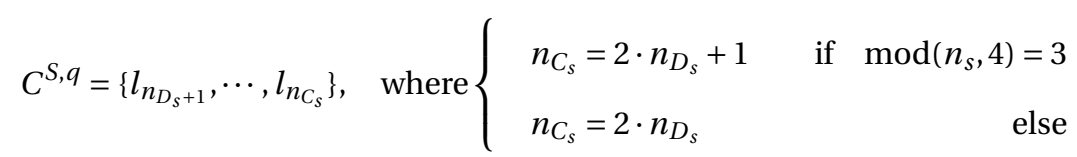

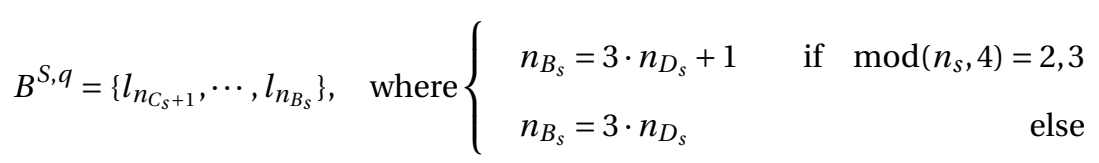

$$
\begin{aligned}
& A^{S, q}=\left\{l_{n_{B_{S}+1}}, \cdots, l_{n_{s}}\right\} \\
& K_{j}^{S, q}=\left\{\begin{array}{cc}
A, & \text { if } j \in A^{S, q}, \\
B, & \text { if } j \in B^{S, q}, \\
C, & \text { if } j \in C^{S, q}, \\
D, & j \in D^{S, q} .
\end{array}\right.
\end{aligned}
$$

ESG class weight of asset $\mathrm{j}$ in period $q$ :

$$
\alpha_{j}^{q}=\frac{M_{j}}{\sum_{\substack{j^{\prime} \in[1, n] \\ j^{\prime}: K^{S, q}=K_{j}^{S, q}}} M_{j^{\prime}}} \text { for } \forall_{j, S, q}
$$

Appendix A.4. Values of ESG class $k$ in period $q$ at trading day $t$ :

$$
\boldsymbol{I}_{t, k}^{q}=\sum_{\substack{j^{\prime} \in[1, n] \\ j^{\prime}: K_{j^{\prime}}^{S, q}=k}} \alpha_{j^{\prime}}^{q} \cdot Y_{t, j^{\prime}, k}^{q} \text { for } \forall_{q, k} \text { and } t \in T_{q} \text {, }
$$

where $T_{1}=[1,1260], T_{2}=[1261,2517], T_{3}=[2518,3271]$. 


\section{Appendix B. Two-Step Inference for Margins}

As financial data are strongly dependent on past values and not uniformly distributed on $[0,1]^{d}$, which is the necessary input for a copula, a two-step inference for margins (IFM) approach is followed. This approach as been investigated by Joe (2005). We follow a parametric marginal model and estimate the margins first, we then use the estimated marginal distributions to transform the data on the copula scale by defining the pseudo-copula data. This allows us to remove the marginal time dependence by utilizing standard univariate time series models and then proceed with standardized residuals obtained from these models. We fit a generalized autoregressive conditional heteroskedasticity (GARCH) model with Student $t$ innovations to our data, allowing for time-varying volatility and volatility clustering.

\begin{tabular}{|c|c|}
\hline Parameters & Notation \\
\hline The set of trading days in period $q$ & $p_{q}$ with $p_{0}=\varnothing, p_{1}=\{1, \ldots, 1260\}, p_{2}=\{1261, \ldots, 2517\}, p_{3}=\{2518, \ldots, 3271\}$ \\
\hline S\&P $500 \log$ returns in period $q$ & $\boldsymbol{I}^{M, q}=\left(I_{1+\left|p_{q-1}\right|}^{M}, \ldots, I_{\left|p_{q-1}\right|+\mid p_{q}}^{M}\right)^{\top} \in \mathbb{R}^{\left|p_{q}\right|}$ \\
\hline Matrix of $\log$ returns $Y_{t, j}$ in sector and period $q$ for $T \in t_{q}$ & $Y^{q}=\left[\boldsymbol{Y}_{1}, \ldots, \boldsymbol{Y}_{n}\right] \in \mathbb{R}^{\left|p_{q}\right| \times n}$, where $\boldsymbol{Y}_{j^{\prime}}=\left(Y_{1+\left|p_{q-1}\right|, j^{\prime}}, \ldots, Y_{\left|p_{q-1}\right|+\left|p_{q}\right|, j^{\prime}}\right)^{\top}, j^{\prime} \in[1, n]$ \\
\hline Data matrix for in period $q$ & $X^{q}=\left[Y^{q}, \boldsymbol{I}^{q}, \boldsymbol{I}_{A}^{q}, \boldsymbol{I}_{B}^{q}, \boldsymbol{I}_{C}^{q}, \boldsymbol{I}_{D}^{q}\right] \in \mathbb{R}^{\left|p_{q}\right| \times P}$ \\
\hline Columns of the data matrix $X^{q}$ & $d=1, \ldots, P$ \\
\hline Rows of the data matrix $X^{q}$ & $i=1, \ldots,\left|p_{q}\right|$ \\
\hline Column $d$ of the data matrix $X^{q}$ & $\boldsymbol{X}_{d}^{q}=\left(X_{1, d}^{q}, \ldots, X_{\left|p_{q}\right|, d}^{q}\right)^{\top} \in \mathbb{R}^{\left|p_{q}\right|}$ \\
\hline Conditional variance vector of $\boldsymbol{X}_{t, d}^{q}$ on trading day $t$ & $\left(\sigma_{d, t}^{q}\right)^{2}$ \\
\hline Estimated degree of freedom for $\boldsymbol{X}_{t, d}^{q}$ & $\hat{v}_{d}$ \\
\hline Estimated covariance for $\boldsymbol{X}_{d}^{q}$ on trading day $t$ & $\hat{\sigma}_{d, t}^{2}$ \\
\hline Estimated distribution function of the innovation distribution for time series $\boldsymbol{X}_{t, d}^{q}$ & $\hat{F}_{d}^{q}\left(\cdot ; \hat{v}_{d}\right)$ \\
\hline Estimated u-data for an observation $X_{t, d}^{q}$ in period $q$ & $\hat{u}_{t, d}^{q}$ where $t \in T_{q}$ \\
\hline
\end{tabular}

Table B.4: Notation of the GARCH and Copula model.

As an input of a R-vine model in period $q$, we have a data matrix $X^{q}$ defined in Table B.4

In period $q$, we fit a GARCH $(1,1)$ model with appropriate error distribution for a marginal time series, $\boldsymbol{X}_{d}^{q}$, and estimate the parameters of the following model:

$$
\varepsilon_{d, t}^{q}=\sigma_{t, d}^{q} \cdot z_{t} \quad\left(\sigma_{d, t}^{q}\right)^{2}=\gamma_{0}+\gamma_{1} \cdot\left(\varepsilon_{t-1, d}^{q}\right)^{2}+\beta_{1} \cdot\left(\sigma_{t-1, d}^{q}\right)^{2}
$$

where $\left(z_{t}\right)_{t>1}$ is a sequence of normal random independent and identically distributed random variables satisfying the standard assumptions $E\left[z_{t}\right]=0$ and $\operatorname{var}\left[z_{t}\right]=1$ and follows a Student's $t$ distribution. Then using the cumulative distribution function of the standardized Student's $t$ distribution, we determine the pseudo-copula data with the probability integral transformation (PIT), i.e.

$$
\hat{u}_{t, d}^{q}:=\hat{F}_{d}\left(\frac{X_{t, d}^{q}}{\hat{\sigma}_{t, d}} ; \hat{v}_{d}\right)
$$


Following this two-step approach allows us to convert data to the copula scale, which serves as the input for our R-vine copula ESG risk model.

\section{Appendix C. Choosing the Bivariate Copula Families and Estimating the Copula Parameters}

Then, from the set of bivariate copula families in Table C.5 the optimal pair copula families for the variable pairs are selected using the Akaike Information Criterion (AIC) (Akaike, 1998), which has been shown to have good copula family selection properties and high accuracy (Brechmann 2010). Since each pair copula family can be specified sequentially and independently at the same tree level, an alternative selection criteria like the BIC would not be needed to induce sparsity at this step. In the next step, we compute the pseudo copula data as defined in Appendix B and also more detailed in Czado (2019) for the second tree level $T_{2}$, using the estimated pair copulas in the first tree level $T_{1}$. This input data is similarly used to select the second tree level $T_{2}$ of the vine and corresponding pair copula families with their parameters. The approach continues sequentially up to the last tree level. Following this method, we select the pair copula families, fit the five vine trees, and estimate the parameter values. As we choose a pair copula family corresponding to each edge separately, the parameter estimation step is at most a two-dimensional optimization, which is computationally efficient. Moreover, the performance of this method is satisfactory compared to the full log likelihood method, which could be computationally intractable in high dimensions $($ Haff 2012). More details about R-vines and vine trees are given by Kurowicka \& Cooke (2006); Kurowicka \& Joe (2011); Joe (2014); and Czado 2019).

\begin{tabular}{l|ccccccc|ccc}
\hline & \multicolumn{7}{|c|}{ Itau $^{1}$ Copulas } & \multicolumn{3}{c}{ BB Copulas } \\
\hline Properties & $t$ & $F$ & $N$ & $C$ & $J$ & $G$ & $I$ & $B B 1$ & $B B 7$ & $B B 8$ \\
\hline \hline Positive Dependence & $\checkmark$ & $\checkmark$ & $\checkmark$ & $\checkmark$ & $\checkmark$ & $\checkmark$ & - & $\checkmark$ & $\checkmark$ & $\checkmark$ \\
Negative Dependence & $\checkmark$ & $\checkmark$ & $\checkmark$ & - & - & - & - & - & - & - \\
Tail Asymmetry & - & - & - & $\checkmark$ & $\checkmark$ & $\checkmark$ & - & $\checkmark$ & $\checkmark$ & $\checkmark$ \\
Lower Tail Dependence & $\checkmark$ & - & - & $\checkmark$ & - & - & - & $\checkmark$ & $\checkmark$ & - \\
Upper Tail Dependence & $\checkmark$ & - & - & - & $\checkmark$ & $\checkmark$ & - & $\checkmark$ & $\checkmark$ & $\checkmark$ \\
\hline
\end{tabular}

Table C.5: Parametric copula families and their properties without rotations and reflections. Notation of copula families: $\mathrm{t}=$ Student's $\mathrm{t}$, $\mathrm{F}=$ Frank, N = Gaussian, C = Clayton, J = Joe, G = Gumbel, $\boldsymbol{I}=$ Independence, BB1 = Clayton- Gumbel, BB7 = Joe-Clayton, BB8= Extended Joe.

${ }^{1}$ Copula families for which the parameter estimation by Kendall's $\tau$ inversion is available without rotations.

To extend the range of dependence, counterclockwise rotations and reflections of the copula density are included. This allows the Gumbel, Clayton, Joe, BB1, BB7 and BB8 to also accommodate negative dependence $(\tau<0)$. For more details, we refer to Chapter 3 of Czado (2019).

\section{Appendix D. Model Fit}

Appendix D.1. mBIC of the R-vine copula ESG risk model with three specifications

Comparison of the itau and parametric and Gaussian R-vine models. 


\begin{tabular}{l|l|llll}
\hline Model & Year & nobs & logLik & npars & mBIC \\
\hline itau & $2006-2010$ & 1260 & 133415.85 & 2300 & $\mathbf{- 2 4 1 6 8 1 . 5 2}$ \\
par & $2006-2011$ & 1260 & 133730.31 & 2427 & -241396.61 \\
gaus & $2006-2012$ & 1260 & 123607.92 & 1680 & -226242.07 \\
\hline itau & $2011-2015$ & 1257 & 132119.36 & 1975 & $\mathbf{- 2 4 1 5 6 4 . 5 1}$ \\
par & $2011-2016$ & 1257 & 132430.2 & 2118 & -241174.01 \\
gaus & $2011-2017$ & 1257 & 123696.65 & 1680 & -226423.54 \\
\hline itau & $2016-2018$ & 754 & 52671.04 & 1843 & $\mathbf{- 8 4 8 8 4 . 9 9}$ \\
par & $2016-2019$ & 754 & 52882.97 & 1944 & -84646.93 \\
gaus & $2016-2020$ & 754 & 48514.13 & 1680 & -76917.14 \\
\hline
\end{tabular}

Table D.6: Model fit for each model at different time interval $q$ - decision measure mBIC [Nagler et al. [2019]. Additional information are available upon author request. 
Appendix D.2. Copula Families Estimated from 7 different copula families and their rotations

\begin{tabular}{|c|c|c|c|c|c|c|c|c|c|}
\hline \multirow{2}{*}{$\begin{array}{l}\text { Copula Family \& Rotation } \\
\text { Year }\end{array}$} & \multicolumn{3}{|c|}{ Itau Copula Families } & \multicolumn{3}{|c|}{ Parametric Copula Families } & \multicolumn{3}{|c|}{ Gaussian Copula Families } \\
\hline & $2006-2010$ & $2011-2015$ & $2016-2018$ & $2006-2010$ & 2011-2015 & $2016-2018$ & $2006-2010$ & 2011-2015 & 2016-2018 \\
\hline Studentst & 325 & 319 & 289 & 287 & 296 & 234 & 0 & 0 & 0 \\
\hline Clayton & 0 & 0 & 1 & 0 & 0 & 1 & 0 & 0 & 0 \\
\hline Frank & 8 & 9 & 15 & 3 & 5 & 10 & 0 & 0 & 0 \\
\hline Gaussian & 2 & 1 & 20 & 2 & 1 & 16 & 338 & 338 & 338 \\
\hline Gumbel & 0 & 5 & 2 & 0 & 0 & 2 & 0 & 0 & 0 \\
\hline Independence & 0 & 0 & 4 & 0 & 0 & 4 & 0 & 0 & 0 \\
\hline Gumbel $180^{\circ}$ & 3 & 4 & 7 & 0 & 2 & 1 & 0 & 0 & 0 \\
\hline BB1 & 0 & 0 & 0 & 0 & 2 & 0 & 0 & 0 & 0 \\
\hline BB7 & 0 & 0 & 0 & 1 & 0 & 0 & 0 & 0 & 0 \\
\hline BB8 & 0 & 0 & 0 & 15 & 26 & 12 & 0 & 0 & 0 \\
\hline $\mathrm{BB} 190^{\circ}$ & 0 & 0 & 0 & 3 & 0 & 0 & 0 & 0 & 0 \\
\hline BB7 $90^{\circ}$ & 0 & 0 & 0 & 0 & 0 & 1 & 0 & 0 & 0 \\
\hline $\mathrm{BB} 890^{\circ}$ & 0 & 0 & 0 & 2 & 0 & 1 & 0 & 0 & 0 \\
\hline $\mathrm{BB} 1180^{\circ}$ & 0 & 0 & 0 & 2 & 3 & 1 & 0 & 0 & 0 \\
\hline $\mathrm{BB} 7180^{\circ}$ & 0 & 0 & 0 & 3 & 1 & 0 & 0 & 0 & 0 \\
\hline BB8 $180^{\circ}$ & 0 & 0 & 0 & 16 & 12 & 9 & 0 & 0 & 0 \\
\hline $\mathrm{BB} 1270^{\circ}$ & 0 & 0 & 0 & 3 & 0 & 1 & 0 & 0 & 0 \\
\hline $\mathrm{BB} 7270^{\circ}$ & 0 & 0 & 0 & 1 & 2 & 3 & 0 & 0 & 0 \\
\hline BB8 $270^{\circ}$ & 0 & 0 & 0 & 2 & 0 & 1 & 0 & 0 & 0 \\
\hline
\end{tabular}

Table D.7: Bivariate copula families and independence copula fitted for Tree $1\left(T_{1}\right)$. Only copula families which are chosen at least once are presented. Additional vine trees are available upon author request.

\section{Appendix E. Additional Information on Risk Measures}

Appendix E.1. Standard Deviation of Risk Measures

\begin{tabular}{|c|c|c|c|c|c|c|c|c|c|c|c|c|}
\hline Type of Risk & \multicolumn{4}{|c|}{ ESG Risk } & \multicolumn{4}{|c|}{ Market Risk } & \multicolumn{4}{|c|}{ Idiosyncratic Risk } \\
\hline Year & A & $\mathrm{B}$ & $\mathrm{C}$ & $\mathrm{D}$ & A & $\mathrm{B}$ & $\mathrm{C}$ & $\mathrm{D}$ & A & $\mathrm{B}$ & $\mathrm{C}$ & $\mathrm{D}$ \\
\hline $2006-2010$ & 0.124 & 0.087 & 0.086 & 0.086 & 0.102 & 0.056 & 0.058 & 0.074 & 0.088 & 0.080 & 0.075 & 0.074 \\
\hline 2011-2015 & 0.093 & 0.104 & 0.090 & 0.081 & 0.045 & 0.041 & 0.039 & 0.040 & 0.091 & 0.086 & 0.078 & 0.081 \\
\hline $2016-2018$ & 0.178 & 0.123 & 0.125 & 0.124 & 0.036 & 0.040 & 0.037 & 0.042 & 0.163 & 0.118 & 0.120 & 0.114 \\
\hline
\end{tabular}

Table E.8: Standard Deviation values for overall ESG Risk, Market Risk and Idiosyncratic Risk for each ESG Class $k$ in time interval $q$ 


\begin{tabular}{c|cccc|cccc|cccc}
\hline Type of Risk & \multicolumn{4}{|c|}{ ESG Risk } & \multicolumn{4}{c|}{ Market Risk } & \multicolumn{4}{c}{ Idiosyncratic Risk } \\
\hline Year & $\mathrm{A}$ & $\mathrm{B}$ & $\mathrm{C}$ & $\mathrm{D}$ & $\mathrm{A}$ & $\mathrm{B}$ & $\mathrm{C}$ & $\mathrm{D}$ & $\mathrm{A}$ & $\mathrm{B}$ & $\mathrm{C}$ & $\mathrm{D}$ \\
\hline $2006-2010$ & 0.147 & 0.135 & 0.186 & 0.293 & 0.116 & 0.073 & 0.077 & 0.228 & 0.105 & 0.119 & 0.180 & 0.170 \\
$2011-2015$ & 0.295 & 0.207 & 0.215 & 0.166 & 0.020 & 0.026 & 0.018 & 0.016 & 0.293 & 0.207 & 0.215 & 0.167 \\
$2016-2018$ & 0.330 & 0.335 & 0.348 & 0.303 & 0.030 & 0.065 & 0.123 & 0.122 & 0.330 & 0.331 & 0.342 & 0.278 \\
\hline
\end{tabular}

Table E.9: Standard Deviation values for lower tail ESG risk, Market Risk and Idiosyncratic Risk for each ESG Class $k$ in time interval $q$

\section{References}

Aas, K., Czado, C., Frigessi, A., \& Bakken, H. (2009). Pair-copula constructions of multiple dependence. Insurance: Mathematics and Economics, 44, 182-198. URL: http://dx.doi.org/10.1016/j.insmatheco.2007.02.001 doi 10.1016/j.insmatheco.2007.02.001

Abakah, E. J. A., Addo Jr, E., Gil-Alana, L. A., \& Tiwari, A. K. (2021). Re-examination of international bond market dependence: Evidence from a pair copula approach. International Review of Financial Analysis, 74, 101678.

Achim, M.-V., \& Borlea, S. N. (2015). Developing of esg score to assess the non-financial performances in romanian companies. Procedia Economics and Finance, 32, 1209-1224. doi https://doi.org/10.1016/S2212-5671(15)01499-9 Emerging Markets Queries in Finance and Business 2014, EMQFB 2014, 24-25 October 2014, Bucharest, Romania.

Akaike, H. (1998). Information theory and an extension of the maximum likelihood principle. In Parzen E., Tanabe K., Kitagawa G. (eds) Selected Papers of Hirotugu Akaike. Springer Series in Statistics (Perspectives in Statistics). Springer. doi https://doi.org/10.1007/ 978-1-4612-1694-0_15

Albuquerque, R., Koskinen, Y., Yang, S., \& Zhang, C. (2020). Resiliency of environmental and social stocks: An analysis of the exogenous COVID-19 market crash. Review of Corporate Finance Studies, 9, 593-621.

Ane, T., \& Kharoubi, C. (2003). Dependence structure and risk measure. Journal of Business, 76, 411-438.

Ashwin Kumar, N. C., Smith, C., Badis, L., Wang, N., Ambrosy, P., \& Tavares, R. (2016). ESG factors and risk-adjusted performance: a new quantitative model. Journal of Sustainable Finance \& Investment, 6, 292-300.

Auer, B. R., \& Schuhmacher, F. (2016). Do socially (ir) responsible investments pay? New evidence from international ESG data. The Quarterly Review of Economics and Finance, 59, 51-62.

Bae, K.-H., El Ghoul, S., Guedhami, O., Kwok, C. C. Y., \& Zheng, Y. (2019). Does corporate social responsibility reduce the costs of high leverage? Evidence from capital structure and product market interactions. Journal of Banking \& Finance, 100, 135-150.

Becchetti, L., Ciciretti, R., \& Hasan, I. (2015). Corporate social responsibility, stakeholder risk, and idiosyncratic volatility. Journal of Corporate Finance, 35, 297-309.

Bedford, T., \& Cooke, R. M. (2001). Probability density decomposition for conditionally dependent random variables modeled by vines. Annals of Mathematics and Artificial intelligence, 32, 245-268.

Bedford, T., \& Cooke, R. M. (2002). Vines : A New Graphical Model for Dependent Random Variables. Annals of Statistics, 30, 1031-1068.

BenSaïda, A. (2018). The contagion effect in European sovereign debt markets: A regime-switching vine copula approach. International Review of Financial Analysis, 58, 153-165.

Berg, E., \& Lange, K. W. (2020). Enhancing ESG-Risk Modelling-A study of the dependence structure of sustainable investing. Master's thesis KTH Royal Institute of Technology. URL:http://hdl handle .net/2445/169669 accessed on 03-11-2021.

Berg, F., Fabisik, K., \& Sautner, Z. (2021). Is History Repeating Itself? The (Un) predictable Past of ESG Ratings. European Corporate Governance Institute - Finance Working Paper, 708/2020. doi 10.2139/ssrn. 3722087 Accessed on 03-11-2021.

Berg, F., Koelbel, J. F., \& Rigobon, R. (2019). Aggregate Confusion: The Divergence of ESG Ratings. SSRN Electronic Journal, . doi 10.2139/ Ssrn.3438533 Accessed on 03-11-2021. 
Bhattacharya, S., \& Sharma, D. (2019). Do environment, social and governance performance impact credit ratings: a study from India. International Journal of Ethics and Systems, 35, 466-484.

Bhatti, M. I., \& Nguyen, C. C. (2012). Diversification evidence from international equity markets using extreme values and stochastic copulas. Journal of International Financial Markets, Institutions and Money, 22, 622-646.

Billio, M., Costola, M., Hristova, I., Latino, C., \& Pelizzon, L. (2021). Inside the ESG Ratings:(Dis) agreement and performance. Corporate Social Responsibility and Environmental Management, 28, 1426-1445.

Bouslah, K., Kryzanowski, L., \& M'Zali, B. (2018). Social performance and firm risk: Impact of the financial crisis. Journal of Business Ethics, $149,643-669$.

Brechmann, E. (2010). Truncated and simplified regular vines and their applications. Master's thesis Technical University of Munich. URL: https://mediatum.ub.tum.de/doc/1079285/1079285.pdf accessed on 03-11-2021.

Brechmann, E. C., \& Czado, C. (2013). Risk management with high-dimensional vine copulas: An analysis of the Euro Stoxx 50. Statistics and Risk Modeling, 30, 307-342.

Breedt, A., Ciliberti, S., Gualdi, S., \& Seager, P. (2019). Is ESG an Equity Factor or Just an Investment Guide? Journal of Investing, $28,32-42$.

Breuer, W., Müller, T., Rosenbach, D., \& Salzmann, A. (2018). Corporate social responsibility, investor protection, and cost of equity: A crosscountry comparison. Journal of Banking \& Finance, 96, 34-55.

Broadstock, D. C., Chan, K., Cheng, L. T. W., \& Wang, X. (2021). The role of ESG performance during times of financial crisis: Evidence from COVID-19 in China. Finance Research Letters, 38, 101716.

Campbell, J. Y., Lettau, M., Malkiel, B. G., \& Xu, Y. (2001). Have individual stocks become more volatile? An empirical exploration of idiosyncratic risk. Journal of Finance, 56, 1-43.

Capelle-Blancard, G., Crifo, P., Diaye, M.-A., Oueghlissi, R., \& Scholtens, B. (2019). Sovereign bond yield spreads and sustainability: An empirical analysis of OECD countries. Journal of Banking \& Finance, 98, 156-169.

Chan, P. T., \& Walter, T. (2014). Investment performance of "environmentally-friendly" firms and their initial public offers and seasoned equity offers. Journal of Banking \& Finance, 44, 177-188.

Consolandi, C., Eccles, R. G., \& Gabbi, G. (2020). How material is a material issue? Stock returns and the financial relevance and financial intensity of ESG materiality. Journal of Sustainable Finance \& Investment, 0, 1-24.

Cont, R. (2001). Empirical properties of asset returns: stylized facts and statistical issues. Journal of Quantitative Finance, 1, $223-236$.

Cornell, B. (2021). ESG preferences, risk and return. European Financial Management, 27, 12-19.

Czado, C. (2019). Analyzing dependent data with vine copulas: A practical guide with r. In Lecture Notes in Statistics. Springer. doi 10.1007/ $978-3-030-13785-4$

Czado, C., \& Nagler, T. (2022). Vine copula based modeling. Annual Review of Statistics and Its Application, 9. doi 10.1146/ annurev-statistics-040220-101153

De, I., \& Clayman, M. R. (2015). The benefits of socially responsible investing: An active manager's perspective. Journal of Investing, 24, 49-72.

Demers, E., Hendrikse, J., Joos, P., \& Lev, B. (2021). ESG did not immunize stocks during the COVID-19 crisis, but investments in intangible assets did. Journal of Business Finance \& Accounting, 48, 433-462.

Diemont, D., Moore, K., \& Soppe, A. (2016). The downside of being responsible: Corporate social responsibility and tail risk. Journal of Business Ethics, 137, 213-229.

Dorfleitner, G., Halbritter, G., \& Nguyen, M. (2016). The risk of social responsibility-is it systematic? Journal of Sustainable Finance \& Investment, $6,1-14$

Eccles, R. G., \& Klimenko, S. (2019). The investor revolution. Harvard Business Review, 97, 106-116. 
Embrechts, P., Lindskog, F., \& McNeil, A. (2001). Modelling dependence with copulas. Technical Report Département de mathématiques, Institut Fédéral de Technologie de Zurich, Zurich. URL:http://citeseerx . ist.psu.edu/viewdoc/download?doi=10.1.1.69.792\& rep=rep1\&type=pdf accessed on 03-11-2021.

Embrechts, P., McNeil, A., \& Straumann, D. (2002). Correlation and dependence in risk management: properties and pitfalls volume 1. Cambridge University Press.

European Banking Authority (2018). Sustainable Finance. URL: https://www.eba.europa.eu/financial-innovation-and-fintech/ sustainable-finance accessed on 03-11-2021.

European Banking Authority (2020). EBA Discussion paper on management and supervision of ESG risks for credit institutions and investment firms. Technical Report October. URL: https://www.eba.europa.eu/sites/default/documents/files/document_library/ Publications/Discussions/2021/Discussion $\% 20$ Paper $\% 20$ on $\% 20$ management $\% 20$ and $\% 20$ supervision $\% 20$ of $\% 20$ ESG $\% 20$ risks $\%$, 20 for $\% 20$ credit $\% 20$ institutions $\% 20$ and $\% 20$ investment $\% 20$ irms $/ 935496 / 2020-11-02 \% 20 \% 20$ ESG $\% 20$ Discussion $\% 20$ Paper .

pdf accessed on 03-11-2021.

European Central Bank (2021). Climate-related risk and financial stability. Technical Report. URL:https://www.ecb.europa.eu/pub/pdf/ other/ecb.climateriskfinancialstability202107\{ $\} 87822$ fae81.en.pdf accessed on 03-11-2021.

Fenech, J. P., Vosgha, H., \& Shafik, S. (2015). Loan default correlation using an Archimedean copula approach: A case for recalibration. Economic Modelling, 47, 340-354.

Fink, H., Klimova, Y., Czado, C., \& Stöber, J. (2017). Regime Switching Vine Copula Models for Global Equity and Volatility Indices. Econometrics, $5,1-38$.

Flori, A., Lillo, F, Pammolli, F., \& Spelta, A. (2021). Better to stay apart: asset commonality, bipartite network centrality, and investment strategies. Annals of Operations Research, 299, 177-213.

Frahm, G., Junker, M., \& Schmidt, R. (2005). Estimating the tail-dependence coefficient: properties and pitfalls. Insurance: Mathematics and Economics, 37, 80-100.

Friede, G. (2019). Why don't we see more action? A metasynthesis of the investor impediments to integrate environmental, social, and governance factors. Business Strategy and the Environment, 28, 1260-1282.

Gibson, R., Krueger, P., \& Schmidt, P. S. (2020). ESG rating disagreement and stock returns. Swiss Finance Institute Research Paper, . doi 10. 2139/ssrn.3433728 Accessed on 03-11-2021.

Giese, G., Lee, L.-E., Melas, D., Nagy, Z., \& Nishikawa, L. (2019). Foundations of ESG investing: how ESG affects equity valuation, risk, and performance. Journal of Portfolio Management, 45, 69-83.

Global Sustainable Investment Alliance (GSIA) (2018). 2018 Global Sustainable Investment Review. Technical Report. URL: http://www. gsi-alliance.org/wp-content/uploads/2019/06/GSIR__\}Review2018F.pdf accessed on 03-11-2021.

Goldreyer, E. F., \& Diltz, J. D. (1999). The performance of socially responsible mutual funds: Incorporating sociopolitical information in portfolio selection. Managerial Finance, 25, 23-36.

Gormley, T. A., \& Matsa, D. A. (2011). Growing out of trouble? Corporate responses to liability risk. Review of Financial Studies, 24, $2781-2821$. Gormley, T. A., Matsa, D. A., \& Milbourn, T. (2013). CEO compensation and corporate risk: Evidence from a natural experiment. Journal of Accounting and Economics, 56, 79-101.

Haff, I. H. (2012). Comparison of estimators for pair-copula constructions. Journal of Multivariate Analysis, 110, 91-105.

Henriksson, R., Livnat, J., Pfeifer, P., \& Stumpp, M. (2019). Integrating ESG in portfolio construction. Journal of Portfolio Management, 45, $67-81$.

Hoepner, A. G. F., Oikonomou, I., Sautner, Z., Starks, L. T., \& Zhou, X. (2016). \{ESG\} Shareholder Engagement and Downside Risk. SSRN 
Electronic Journal, . doi $10.2139 /$ ssrn. 2874252

Joe, H. (1996). Families of $\mathrm{m}$-variate distributions with given margins and $\mathrm{m}(\mathrm{m}-1) / 2$ bivariate dependence parameters. Lecture NotesMonograph Series, 28, 120-141.

Joe, H. (2005). Asymptotic efficiency of the two-stage estimation method for copula-based models. Journal of Multivariate Analysis, 94, 401419.

Joe, H. (2014). Dependence modeling with copulas. USA: CRC press.

Joe, H., \& Xu, J. J. (1996). The Estimation Method of Inference Functions for Margins for Multivariate Models. Technical Report 166 Department of Statistics, University of British Columbia. doi 10.14288/1.0225985 accessed on 03-11-2021.

Jondeau, E., \& Rockinger, M. (2003). Testing for differences in the tails of stock-market returns. Journal of Empirical Finance, 10, 559-581.

Kelly, B., \& Jiang, H. (2014). Tail risk and asset prices. Review of Financial Studies, 27, 2841-2871.

Kim, Y., Li, H., \& Li, S. (2014). Corporate social responsibility and stock price crash risk. Journal of Banking \& Finance, 43, 1-13.

Kurowicka, D., \& Cooke, R. M. (2006). Uncertainty analysis with high dimensional dependence modelling. UK: John Wiley \& Sons.

Kurowicka, D., \& Joe, H. (2011). Dependence modeling - handbook on vine copulae. Singapore: World Scientific Publishing Co.

Li, D. X. (2000). On default correlation: A copula function approach. Journal of Fixed Income, 9, 43-54.

Li, F., \& Polychronopoulos, A. (2020). What a difference an esg ratings provider makes. URL: https://www.researchaffiliates . com/ documents/770-what-a-difference-an-esg-ratings-provider-makes .pdf accessed on 03-11-2021.

Li, X., Wang, S. S., \& Wang, X. (2017). Trust and stock price crash risk: Evidence from China. Journal of Banking \& Finance, 76, 74-91.

Lööf, H., Sahamkhadam, M., \& Stephan, A. (2021). Is Corporate Social Responsibility investing a free lunch? The relationship between ESG, tail risk, and upside potential of stocks before and during the COVID-19 crisis. URL: http://www. cesis . se accessed on 03-11-2021.

Luo, X., \& Bhattacharya, C. B. (2009). The debate over doing good: Corporate social performance, strategic marketing levers, and firmidiosyncratic risk. Journal of Marketing, 73, 198-213.

Maiti, M. (2020). Is ESG the succeeding risk factor? Journal of Sustainable Finance \& Investment, 11, 1-15.

Malevergne, Y., Pisarenko, V., \& Sornette, D. (2005). Empirical distributions of stock returns: between the stretched exponential and the power law? Quantitative Finance, 5, 379-401.

Minor, D. B. (2011). Corporate citizenship as insurance: Theory and evidence. University of California, Berkley, .

Nagler, T., Bumann, C., \& Czado, C. (2019). Model selection in sparse high-dimensional vine copula models with an application to portfolio risk. Journal of Multivariate Analysis, 172, 180-192.

Naifar, N. (2012). Modeling the dependence structure between default risk premium, equity return volatility and the jump risk: Evidence from a financial crisis. Economic modelling, 29, 119-131.

Nguyen, C. C., \& Bhatti, M. I. (2012). Copula model dependency between oil prices and stock markets: Evidence from China and Vietnam. Journal of International Financial Markets, Institutions and Money, 22, 758-773.

Nofsinger, J., \& Varma, A. (2014). Socially responsible funds and market crises. Journal of Banking \& Finance, 48, $180-193$.

Pourkhanali, A., Kim, J.-M., Tafakori, L., \& Fard, F. A. (2016). Measuring systemic risk using vine-copula. Economic modelling, 53, 63-74.

Puccetti, G., \& Scherer, M. (2018). Copulas, credit portfolios, and the broken heart syndrome. Dependence Modeling, 6, 114-130.

Refinitiv (2021). Environmental, Social and Governance (ESG) scores from Refinitiv. URL: https://www.refinitiv.com/content/dam/ marketing/en_us/documents/methodology/refinitiv-esg-scores-methodology.pdf accessed on 03-11-2021.

Sahin, Ö., Bax, K., Paterlini, S., \& Czado, C. (2021). ESGM: ESG scores and the Missing pillar. SSRN Electronic Journal, . doi 10.2139/ssrn. 3890696

Salmon, F. (2012). The formula that killed Wall Street. Significance, 9, 16-20. 
Schwarz, G. (1978). Estimating the dimension of a model. The Annals of Statistics, 6, 461-464.

Serafeim, G., \& Yoon, A. (in press). Stock Price Reactions to ESG News: The Role of ESG Ratings and Disagreement. Review of Accounting Studies, . doi 10.2139/ssrn.3765217 Accessed on 03-11-2021.

Shafer, M., \& Szado, E. (2018). Environmental, social, and governance practices and perceived tail risk. Accounting \& Finance, 60, $4195-4224$. doi $10.1111 /$ acfi.12541

Sherwood, M. W., \& Pollard, J. L. (2017). The risk-adjusted return potential of integrating ESG strategies into emerging market equities. Journal of Sustainable Finance \& Investment, 8, 26-44.

Shirvani, A., \& Volchenkov, D. (2019). A regulated market under sanctions: On tail dependence between oil, gold, and Tehran stock exchange index. URL: https://arxiv.org/abs/1911.01826 doi arXiv:1911.01826 accessed on 03-11-2021.

Sklar, A. (1959). Fonctions de repartition an dimensions et leurs marges. Publications de l'Institut de Statistique de l'Universite de Paris, 8, 229-231.

Wamba, L. D., Sahut, J.-M., Braune, E., Teulon, F., \& Others (2020). Does the optimization of a company's environmental performance reduce its systematic risk? New evidence from European listed companies. Corporate Social Responsibility and Environmental Management, 27, $1677-1694$

$\mathrm{Xu}$, Q., \& Li, X.-M. (2009). Estimation of dynamic asymmetric tail dependences: an empirical study on Asian developed futures markets. Applied Financial Economics, 19, 273-290.

Zhang, J., De Spiegeleer, J., \& Schoutens, W. (2021). Implied Tail Risk and ESG Ratings. Mathematics, 9, 1611. 